\title{
Foscarnet Therapy for Pure Red Cell Aplasia Related to Human Parvovirus BI9 Infection in Kidney Transplant Recipients: A Preliminary Exploration
}

\author{
Yedong Yu' \\ Ruijie Bao' \\ Junhao Lyu ${ }^{1-4}$ \\ Jianyong $\mathrm{Wu}^{\mathrm{I}-4}$ \\ Jianghua Chen ${ }^{1-4}$ \\ Wenhan Peng ${ }^{1-4}$ \\ 'Department of Kidney Disease Center, \\ The First Affiliated Hospital Zhejiang \\ University School of Medicine, Hangzhou, \\ People's Republic of China; ${ }^{2}$ Department \\ of Kidney Disease Immunology \\ Laboratory, State Administration of \\ Traditional Chinese Medicine of China, \\ Hangzhou, People's Republic of China; \\ ${ }^{3}$ Department of Key Laboratory of \\ Multiple Organ Transplantation, Ministry \\ of Health of China, Hangzhou, People's \\ Republic of China; ${ }^{4}$ Institute of \\ Nephropathy, Zhejiang University, \\ Hangzhou, People's Republic of China
}

Background: Parvovirus B19-associated pure red cell aplasia (PVB19-PRCA) is an uncommon but serious complication after kidney transplantation. Currently, intravenous immunoglobulin (IVIG) is preferred as the first-line treatment for PVB19-PRCA, but presents with disadvantages of disease recurrence and expensive cost. In this context, we propose that foscarnet therapy for kidney transplantation recipients (KTR) with PVB19-PRCA may be an alternative scenario. No related study has been reported, and we performed this study to assess the efficacy and safety of foscarnet for PVB19-associated PRCA in KTR.

Methods: We conducted a retrospective review of PVB19-PRCA in KTR at our center over 9 -year period. The data on therapy and outcomes in all cases treated with foscarnet are detailed records and summarized.

Results: Among our 68 patients, PVB19-PRCA was confirmed in 50 based on inclusion/ exclusion criteria. All patients presented with refractory anemia and low reticulocyte percentage $(<0.5 \%)$, the mean hemoglobin of patients was $79.8 \pm 12.6 \mathrm{~g} / \mathrm{L}$ at the time of PVB19-PRCA was identified. The median serum genome copy number of parvovirus B19 at diagnosis was $9.6 \log _{10}$ copies per milliliter. A total of 11 patients received foscarnet therapy, of 10 patients responded well to the treatment and maintained no recurrence. But 1 patient had a poor response to foscarnet therapy. Except for this patient, the mean hemoglobin level gradually increased from $68.5 \pm 9.3 \mathrm{~g} /$ $\mathrm{L}$ to $73.2 \pm 8.8 \mathrm{~g} / \mathrm{L}$, and the mean percentage of reticulocytes steadily increased from $0.1 \pm 0.0 \%$ to $7.6 \pm 2.9 \%$ after foscarnet therapy. The median serum genome copy number of parvovirus B19 decreased from $9.8 \log _{10}$ to $6.1 \log _{10}$ copies per milliliter. There was no significant difference $(\mathrm{P}=0.61,0.60)$ in serum creatinine and glomerular filtration rate before and after foscarnet treatment. At the latest follow-up, the mean hemoglobin was $131.5 \pm 12.5 \mathrm{~g} / \mathrm{L}$ and the hemoglobin correction occurred in all patients.

Conclusion: Foscarnet therapy doesn't seem to be worse than IVIG for PVB19-PRCA in KTR, and it can be an alternative option.

Keywords: human parvovirus B19, pure red cell aplasia, foscarnet therapy, kidney transplantation

\section{Introduction}

Human parvovirus B19 is a small non-enveloped single-stranded linear DNA virus of the family Parvoviridae. ${ }^{1}$ In 1975, Yvonne Cossart first discovered parvovirus particles, which were detected in the serum number 19 of panel B, hence the name. ${ }^{2}$ It has been
Correspondence: Wenhan Peng Kidney Disease Center, The First Affiliated Hospital, College of Medicine, Zhejiang University, 79 Qingchun Road, Hangzhou, 310003, People's Republic of China

Tel +86 57I-8723687I

Email I198027@zju.edu.cn 
proven that parvovirus B19 targets the erythroid precursor progenitors predominantly in the bone marrow, inducing apoptosis in infected target cell and resulting in acute and chronic anemia. ${ }^{3}$ Parvovirus B19 can have a variety of clinical manifestations under diverse situations. For immunocompromised population, the common phenomenon in the majority of patients is pure red cell aplasia. It is defined by the lack of mature erythroid erythroblasts, but with the presence of giant pronormoblasts in the bone marrow. ${ }^{4-6}$ Owing to the immunosuppression status, kidney transplant recipients were particularly prone to acquire parvovirus B19 infection. The persistence of refractory anemia with reticulocytopenia in KTR should be alerted for PVB19PRCA, which posed a potential serious threat to the allograft and recipient survival. ${ }^{7}$ At present, there is no codified protocol of treatment in terms of PVB19-PRCA. In the literature review, intravenous immunoglobulin (IVIG) is found to be beneficial in kidney transplant recipients with PVB19PRCA. Nevertheless, the recurrence rate of PRCA was $34 \%$, and the one-year success rate was $47 \%$ following IVIG therapy. ${ }^{8}$ Due to the high cost of the IVIG, repeated relapses have increased the economic burden on individuals even in society, not to mention the side effects of IVIG. Foscarnet is an antivirus drug, which is mainly used to treat CMV, HSV and VZV viral infection in immunocompromised patients. As an analog of pyrophosphate, foscarnet can inhibit the DNA chains from extending further by reversibly and selectively blocking the binding site of the viral DNA polymerase enzyme. ${ }^{9}$ Based on these findings, we initially attempted to use foscarnet in KTR with PVB19-PRCA who were ineffective in multiple courses of IVIG therapy. To our satisfaction, we found that foscarnet therapy seems to be working well in these patients. Therefore, on this basis, we preliminarily explored the efficacy and safety of foscarnet therapy in kidney transplantation recipients with new-onset PVB19-PRCA.

\section{Patients and Methods Study Population}

We retrospectively reviewed all cases of KTR with PVB19PRCA between January 2011 and December 2019 in the center of kidney disease, the first affiliated hospital, College of Medicine, Zhejiang University. Recipients, who received kidney transplantation in combination with another organ, were $\mathrm{ABO}$-incompatible kidney transplantation, and those blood specimens that could not be retained were excluded. We collected all relevant information on their demographics, clinical characteristics, treatment and outcomes. Then, we focused on analysis of the data on therapeutic scenario (previous therapy, duration and dose of foscarnet, adjustment in immunosuppression regimen, blood transfusion) and outcomes (changes in hemoglobin, virologic response, serum creatinine (Scr) and the estimated glomerular filtration rate (eGFR) at the start and end of foscarnet therapy, follow-up, death, cause of death, the latest hemoglobin and the parvovirus B19 copy number) in all cases treated with foscarnet. All data were collected from electronic medical record and kidney transplantation database at our center.

\section{Definitions}

KTR with PVB19-PRCA were included in our study according to the following criteria: (1) severe progressive anemia with no response to erythropoietin (the lowest hemoglobin $<10 \mathrm{~g} / \mathrm{dL}$ ), in the absence of active bleeding, iron and folate deficiency, neoplasms, autoimmune, chronical graft dysfunction and drug-induced PRCA after renal transplantation. (2) Reticulocytes $<0.5 \%$ (3) Standard qualitative or quantitative whole-blood polymerase chain reaction (PCR) positive of Parvovirus B19 (PVB19 DNA level was more than $6 \log _{10}$ copies per milliliter). Human parvovirus B19 DNA was detected by commercial realtime PCR kit (Liferiver ${ }^{\mathrm{TM}}$ Shanghai ZJ Biotechnology Co, Ltd) in whole-blood. Due to the serological detection of immunocompromised patients was unreliable, no antibody of parvovirus B19 was detected in this study. In our study, KTR with good graft function refer to the estimated glomerular filtration rate (eGFR) of more than $45 \mathrm{~mL} / \mathrm{min} /$ $1.73 \mathrm{~m}^{2}$. The eGFR is estimated with the Chronic Kidney Disease Epidemiology Collaboration CKD-EPI formula. Correction of hemoglobin is defined as hemoglobin level more than $10 \mathrm{~g} / \mathrm{dL}$ or back to the level before PVB19PRCA diagnosis.

\section{Treatment}

Recipients who received IVIG therapy were given IVIG $20 \mathrm{~g} /$ day for $5-10$ consecutive days and adjusted for immunosuppression. In case of nonresponse to the first IVIG course or recurrence, another course of IVIG (20g/day for 5-10 days) may be given. In situation of recurrence of IVIG therapy, we decided to switch from IVIG to foscarnet therapy after written informed consent was obtained from patients.

Recipients who received foscarnet therapy were given foscarnet $6 \mathrm{~g}$ /day for 5-14 consecutive days and adjusted the immunosuppression. Recipients treated with foscarnet 
were given 1000 milliliters per day of adequate hydration and were monitored with daily serum creatinine and urine volume closely to prevent foscarnet-associated acute kidney injury.

\section{Induction and Maintenance Immunosuppression}

At our center, induction regimens include rabbit antithymocyte globulin (ATG, $1 \mathrm{mg} / \mathrm{kg} /$ day and a maximum of 5 doses) or interleukin-2 receptor antagonist (basiliximab, $20 \mathrm{mg}$, at days 0 and 4). All patients received methylprednisolone $10 \mathrm{mg} / \mathrm{kg} /$ day on day 0,1 and 2 . Dosage of prednisone was slowly reduced from 60 to $10 \mathrm{mg} / \mathrm{d}$ within one month after KT. Standard triple-drug maintenance immunosuppression consisted of prednisone, tacrolimus, and mycophenolate (EC-MPS or MMF).

\section{Statistical Analysis}

In this study, age, hemoglobin, reticulocytes percentage, serum creatinine, estimated glomerular filtration rate (eGFR), the doses of IVIG and foscarnet are described in the form of mean plus-minus standard deviation (mean $\pm \mathrm{SD}$ ). The serum parvovirus B19 genome copy number and time of parvovirus B19 infection were described as median values with ranges. The copy number of parvovirus B19 genome is expressed by logarithm. Categorical variables are expressed as percentages. Reported P-values were two-sided, and P-values $<0.05$ were considered statistically significant. All analyses were performed using the GraphPad prism 8 software for Windows (Version 8.02).

\section{Ethical Consideration}

The study was approved by the first affiliated hospital of Zhejiang University Ethics Committee Board (Reference Number:20210212A), and all the involved activities were conformed the ethical guidelines of the Declaration of Helsinki. Kidney donations and transplants were also conducted in accordance with the Declaration of Istanbul. Before transplantations, all patients gave written informed consent to use their sample and data for medical research. Individual informed consent for this observational study was obtained before foscarnet therapy. Deceased donor kidneys in this study were procured from donation after the citizens' death in accordance with the guidelines of the National Program for Deceased Organ Donation in China. There is a kinship in all living donor and the corresponding recipients. All donations were voluntary, unpaid and no organs were obtained from prisoners.

\section{Result \\ Baseline Characteristics}

From January 2011 to December 2019, we performed 3328 renal transplantations at our center. Over 9-year period, 68 patients were identified with human parvovirus B19 infection. According to the exclusion criteria, 10 recipients were excluded in this study and only 50 patients fulfilled the included criteria for PRCA (Figure 1). For the first-onset of PVB19-PRCA, 45 patients received IVIG therapy, 5 patients received foscarnet therapy, respectively. In the course of treatment, we switched from IVIG to foscarnet treatment in 6 patients who had 1 or more relapses after several courses of IVIG therapy. We further evaluated the therapeutic effect and safety of foscarnet therapy in a total of 11 patients.

For 50 included patients, the demographic, clinical characteristic, treatment and outcomes are described in Table 1. The mean age was $34.7 \pm 10.4$ years, and 31 (62\%) were living donor KTR; 41 patients received induction therapy, $34(83 \%)$ with basiliximab and 7 (17\%) with anti-human $\mathrm{T}$ lymphocyte rabbit immunoglobulin (ATG). All patients received triple immunosuppression (IS) regimens with prednisone, tacrolimus, and mycophenolate mofetil. The median time to PVB19-PRCA after KT was 34.5 days (ranging from 7 to 666 days). Forty-six patients developed PVB19 infection within 3 months after transplantation, but 1 patient had a late-onset (666 days after $\mathrm{KT}$ ) infection.

\section{Clinical Feature}

All patients presented variable degrees of refractory anemia, and the mean hemoglobin of 50 patients was $112.8 \pm 14.8 \mathrm{~g} / \mathrm{L}$ before $\mathrm{KT}, 79.8 \mathrm{~g} \pm 12.6 \mathrm{~g} / \mathrm{L}$ at the time of PVB19-PRCA was identified. In the process of infection, the lowest value of hemoglobin was $62.4 \pm 13.0 \mathrm{~g} / \mathrm{L}$. All patients had a low reticulocyte percentage $(<0.5 \%)$. Thirty-three recipients underwent a bone marrow examination, 19 (57.6\%) demonstrated PRCA. The median serum genome copy number of parvovirus B19 at diagnosis was $9.6 \log _{10}$ copies per milliliter (ranging from $7.6 \log _{10}$ to $10.8 \log _{10}$ per milliliter). No patients showed up with skin, joint, liver, cardiac or neurological involvement. 


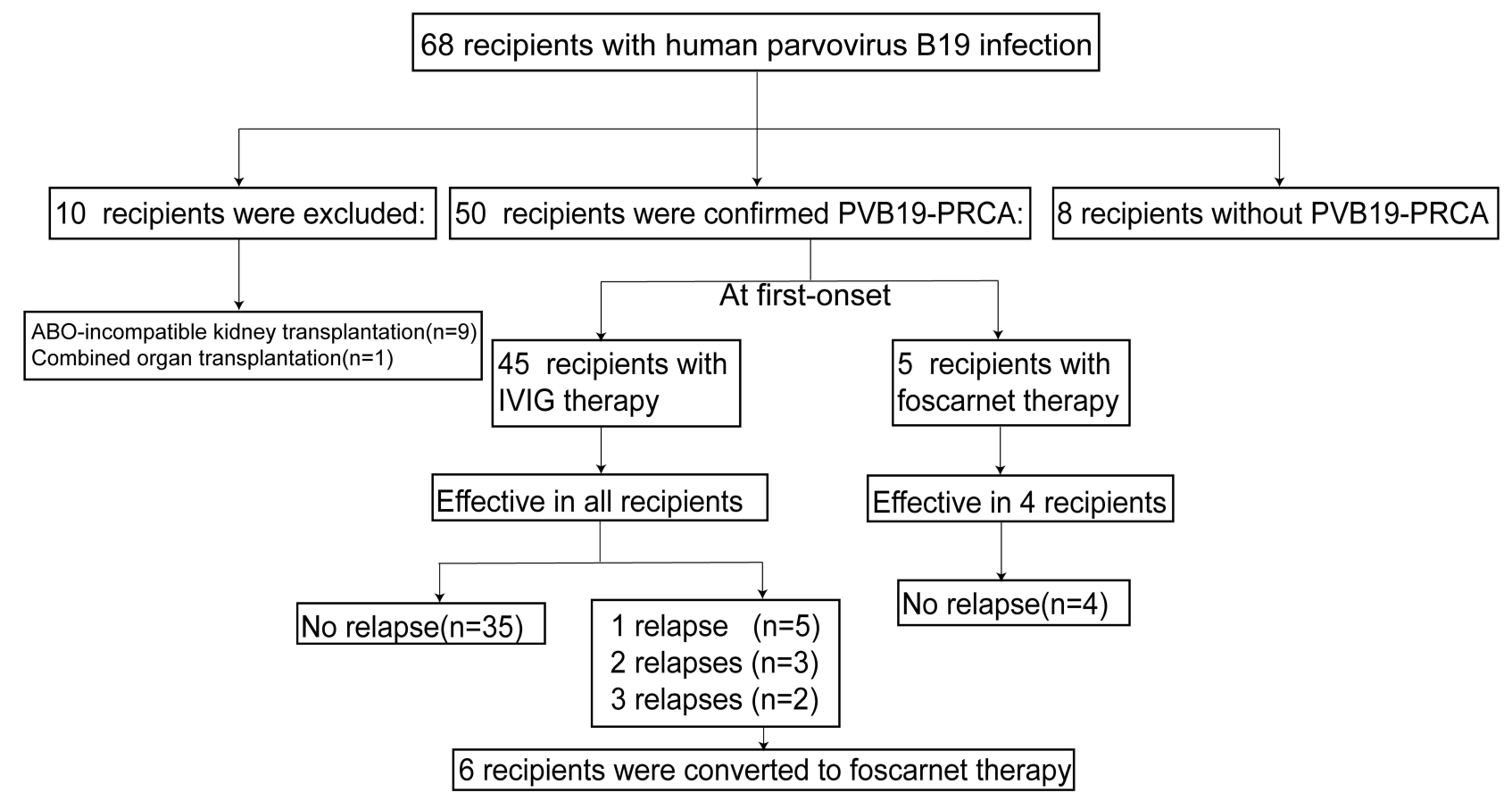

Figure I Final diagnosis of 68 patients for PVBI9 infection between $201 \mathrm{I}$ to 2019.

Abbreviations: PVBI9-PRCA, parvovirus BI9-associated pure red cell aplasia; IVIG, intravenous immunoglobulin.

\section{Treatment}

Forty-five patients received IVIG therapy and 5 patients received foscarnet therapy for the first-onset of PVB19PRCA. At the time of PRCA, the mean tacrolimus trough levels were $6.47 \mathrm{ng} / \mathrm{mL}, 6.55 \mathrm{ng} / \mathrm{mL}$ in IVIG group and foscarnet group, respectively. And the median daily doses for MMF were $1000 \mathrm{mg}$, and for EC-MPS, it was $720 \mathrm{mg}$ in both groups. Forty-four patients $(88 \%)$ were switched from tacrolimus to cyclosporine. And the IS regimens were decreased in all patients upon diagnosis of the disease. Seventeen patients required blood transfusion with an average of 2.3 (range,1-6) packed red blood cells per patient. In summary, for the first course, 45 patients received IVIG at a mean of $2.8 \pm 1.3 \mathrm{~g} / \mathrm{kg}$ for $8.0 \pm 2.4$ days (ranging from 3 to 16 days) and 5 patients received foscarnet therapy at a mean of $1.0 \pm 0.2 \mathrm{~g} / \mathrm{kg}$ for $9.6 \pm 3.2$ days (ranging from 7 to 14 days).

\section{Outcome}

Forty-five patients received IVIG for the first-onset of PVB19-PRCA, and they all had a good response to the treatment. However, 5 patients developed one relapse following the administration of IVIG therapy, 3 patients recurred two times, 2 patients recurred three times and 35 patients did not relapse. There were 6 recipients switched from IVIG to foscarnet therapy due to relapses of IVIG. Hence, a total of 11 patients were treated with foscarnet therapy, and detailed information is shown in Table 2. Ten patients responded well to the foscarnet treatment and maintained no recurrence. However, 1 patient had a poor response to foscarnet therapy. Eventually, following additional 2 courses of IVIG, the patient's condition was well controlled. Except for this patient, the mean hemoglobin level gradually increased from $68.5 \pm 9.3 \mathrm{~g} / \mathrm{L}$ to $73.2 \pm 8.8 \mathrm{~g} / \mathrm{L}$, and the lowest mean hemoglobin value was $56.5 \pm 8.2 \mathrm{~g} / \mathrm{L}$ during foscarnet therapy (Figure 2). The mean percentage of reticulocytes steadily increased from $0.1 \pm 0.0 \%$ to $7.6 \pm 2.9 \%$ (Figure 3). The median serum genome copy number of parvovirus B19 decreased from $9.8 \log _{10}$ to $5.8 \log _{10}$ copies per milliliter. 1 month and 3 months after foscarnet therapy, the mean hemoglobin was $112.5 \pm 8.8 \mathrm{~g} / \mathrm{L}, 125.2$ $\pm 9.0 \mathrm{~g} / \mathrm{L}$, respectively. Before the foscarnet therapy, Scr were at a mean of $122.9 \pm 29.5 \mu \mathrm{mol} / \mathrm{L}$, and the estimated glomerular filtration rate (eGFR) was at a mean of 57.7 $\pm 11.4 \mathrm{~mL} / \mathrm{min} / 1.73 \mathrm{~m}^{2}$ in 11 patients. Accordingly, the Scr were $133.5 \pm 35.9 \mu \mathrm{mol} / 1$ and the eGFR were 56.1 $\pm 14.8 \mathrm{~mL} / \mathrm{min} / 1.73 \mathrm{~m}^{2}$ respectively after the end of foscarnet therapy. There were no significant differences $(\mathrm{P}=0.61$, $0.60)$ in serum creatinine and eGFR before and after foscarnet treatment. Foscarnet is well tolerated without the development of any severe side effects in all patients. 
Table I Demographic, Clinical Characteristic, Treatment and Outcomes of 50 Patients Who Were Confirmed PVBI9-PRCA

\begin{tabular}{|c|c|}
\hline No. of Patients & 50 \\
\hline Age, $y$, mean $\pm S D$ & $34.7 \pm 10.4$ \\
\hline Male & $34(68 \%)$ \\
\hline \multicolumn{2}{|l|}{ Type of KT } \\
\hline DD & $19(38 \%)$ \\
\hline LD & $31(62 \%)$ \\
\hline Dialysis before KT & $44(88 \%)$ \\
\hline $\mathrm{HD}$ & 28 \\
\hline PD & 15 \\
\hline $\mathrm{HD}+\mathrm{PD}$ & I \\
\hline Induction immunosuppression & $41(82 \%)$ \\
\hline ATG & 7 \\
\hline Basiliximab & 34 \\
\hline \multicolumn{2}{|l|}{ Underlying disorder } \\
\hline CGN & 37 \\
\hline $\lg \mathrm{AN}$ & 4 \\
\hline Polycystic kidney & 3 \\
\hline Hypertensive nephropathy & 2 \\
\hline FSGS & 1 \\
\hline Obstructive nephropathy & 1 \\
\hline Purpura nephritis & 1 \\
\hline Alport syndrome & 1 \\
\hline \multicolumn{2}{|l|}{ HLA mismatch } \\
\hline $0-3 / 6$ & $42(84 \%)$ \\
\hline $4-6 / 6$ & $8(16 \%)$ \\
\hline PRA+ & 3 \\
\hline $1+$ & 3 \\
\hline $\begin{array}{l}\text { The median time to the onset after } \\
\text { Kidney transplantations, } d\end{array}$ & 34.5 \\
\hline \multicolumn{2}{|l|}{ Month of occurrence } \\
\hline $\mathrm{I}-3$ & 7 \\
\hline $4-6$ & 22 \\
\hline $7-9$ & 11 \\
\hline $10-12$ & 10 \\
\hline $\begin{array}{l}\text { The median serum genome copy } \\
\text { number of parvovirus B I9, Copies/mL }\end{array}$ & $\begin{array}{l}4.1 \times 10^{\wedge} 9 \\
\left(3.9 \times 10^{\wedge} 7\right. \\
\left.6.8 \times 10^{\wedge} 10\right)\end{array}$ \\
\hline \multicolumn{2}{|l|}{ Hemoglobin, g/L, mean $\pm S D$} \\
\hline $\mathrm{Hb}$ before $\mathrm{KT}$ & $112.8 \pm 14.8$ \\
\hline $\mathrm{Hb}$ at diagnosis & $79.8 \pm 12.6$ \\
\hline $\mathrm{Hb}$ at lowest value & $62.4 \pm 13.0$ \\
\hline
\end{tabular}

(Continued)
Table I (Continued).

\begin{tabular}{|l|l|}
\hline No. of Patients & $\mathbf{5 0}$ \\
\hline Treatment & \\
Patients with IVIG for first-onset, No. & 45 \\
IVIG first does, g/kg, mean \pm SD & $2.8 \pm 1.3$ \\
IVIG duration, d, mean \pm SD & $8.0 \pm 2.4$ \\
Patients with foscarnet for first-onset, No. & 5 \\
$\quad$ Foscarnet dose, g/kg, mean \pm SD & $1.0 \pm 0.2$ \\
$\quad$ Foscarnet duration, d, mean \pm SD & $9.6 \pm 3.2$ \\
Switch (Tacro to Cyclo) & $44(88 \%)$ \\
Requiring blood transfusion & $17 / 50(34 \%)$ \\
\hline Outcomes & \\
Effective in IVIG, NO. & $45 / 45(100 \%)$ \\
Recurrence in IVIG, NO. & $10 / 45(22.2 \%)$ \\
I relapse & 5 \\
2 relapses & 3 \\
3 relapses & 2 \\
Effective in foscarnet, NO. & $4 / 5(80 \%)$ \\
Recurrence in foscarnet, NO. & 0 \\
\hline
\end{tabular}

Abbreviations: $\mathrm{Y}$, year; d, days; $\mathrm{Hb}$, hemoglobin; DD, deceased donor; LD, living donor; KT, kidney transplantation; HD, Hemodialysis; PD, peritoneal dialysis; CGN, Chronic glomerulonephritis; IgAN, Immunoglobulin A nephropathy; FSGS, focal segmental glomerulosclerosis; HLA, human leukocyte antigen; Tacro, tacrolimus; Cyclo, cyclosporine; PRA+, panel reactive antibody positive.

During follow-up, unfortunately 1 patient died of pulmonary infection and meningitis 8 months after kidney transplantation but with good allograft function and other 10 patients remain alive. The median follow-up durations were 19.5 months (ranging from 13 to 114 months) in 10 recipients. Follow-up date for blood B19 DNA PCR was obtained for 8 patients and only one patient turned into negative within 10 months after transplantation. Seven patients had low-level-viremia and no clinical manifestations of parvovirus B19 infection during follow-up (Figure 4). At the latest follow-up, the mean hemoglobin was $131.5 \pm 12.5 \mathrm{~g} / \mathrm{L}$ and the hemoglobin correction occured in all patients (Table 3).

\section{Discussion}

We retrospectively reviewed the data for a series of 50 patients with PVB19-PRCA at our center over a 9-year period. From the literature, the total incidence of parvovirus B19 DNA positive in renal transplant patients is estimated at $10.3 \%$ and PVB19-PRCA occurred in only $3 \%$ renal transplantation recipient. ${ }^{10}$ Since parvovirus B19 


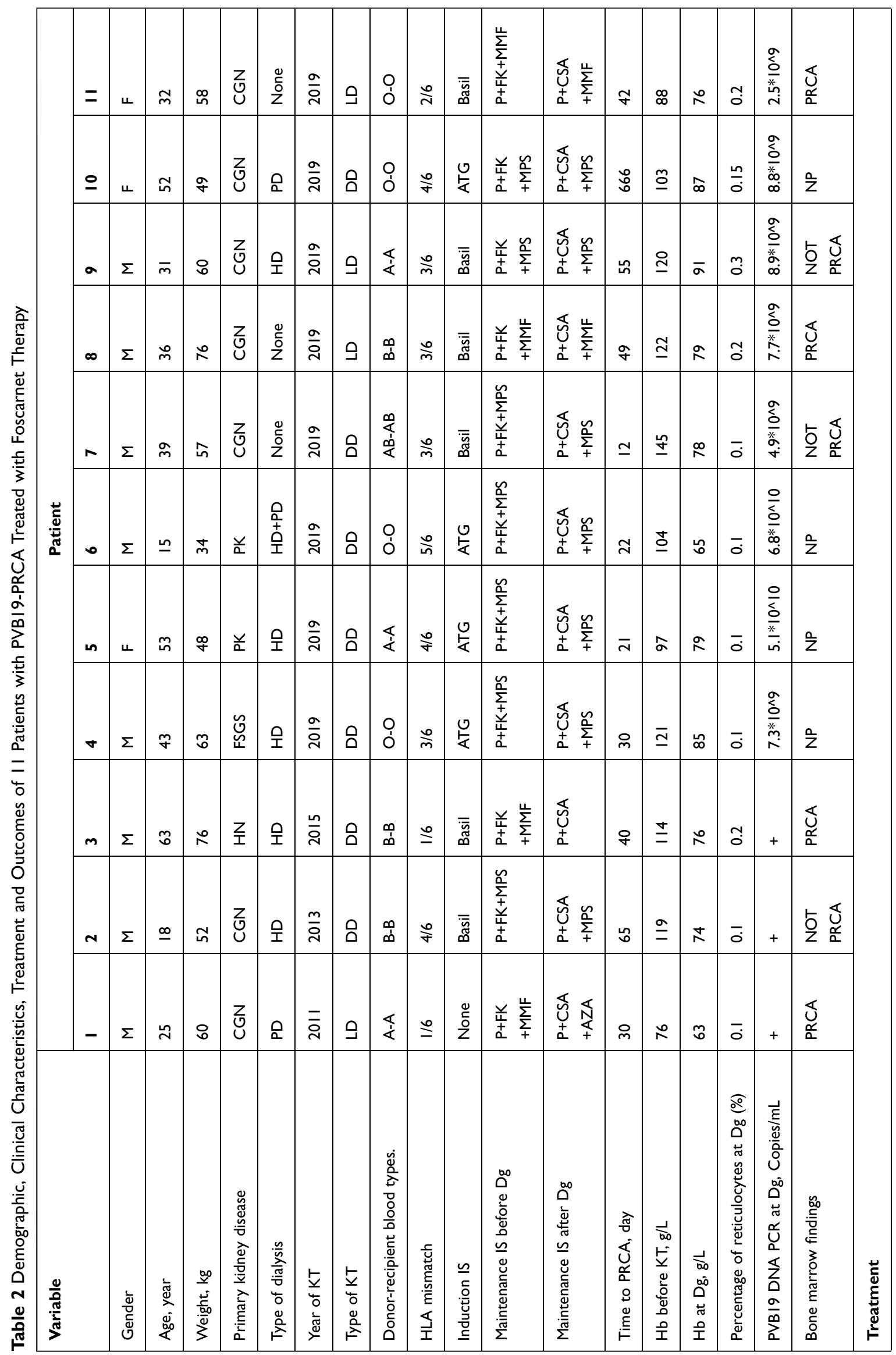




\begin{tabular}{|c|c|c|c|c|c|c|c|c|c|c|c|c|c|c|c|c|c|c|c|}
\hline $\begin{array}{l}\text { Ĩ } \\
\text { Z̃ }\end{array}$ & - & - & - & $\stackrel{+}{\stackrel{m}{-}}$ & $\underline{m}$ & $\stackrel{\check{\nu}}{\check{\nu}}$ & 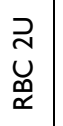 & & ஜ & fo & นn & $\overline{0}$ & กั & 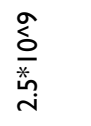 & $\S$ & ํㅡ & $\sigma$ & $\underset{\infty}{m}$ & $\stackrel{\circ}{i}$ \\
\hline $\begin{array}{l}\stackrel{0}{0} \\
\text { o }\end{array}$ & - & - & - & 吕 & $r$ & 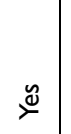 & $\begin{array}{l}\stackrel{0}{0} \\
\text { Z }\end{array}$ & & $\hat{o}$ & $\stackrel{q}{f}$ & นู & $\overline{0}$ & $\stackrel{\sigma}{+}$ & 弚 & 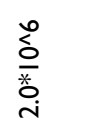 & 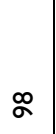 & $\stackrel{\infty}{\underline{\Xi}}$ & 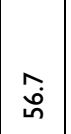 & นn \\
\hline 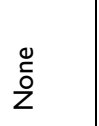 & - & - & - & $\begin{array}{l}R \\
0 \\
0\end{array}$ & $r$ & $\stackrel{\tilde{y}}{\succ}$ & $\begin{array}{l}\stackrel{0}{0} \\
\text { Oे }\end{array}$ & & N & థొ & $\bar{\infty}$ & m. & $\stackrel{m}{a}$ & 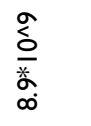 & 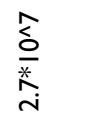 & $\underline{q}$ & $\underline{\mathcal{F}}$ & $\overline{\text { กิ }}$ & $\hat{\text { ค่ }}$ \\
\hline $\begin{array}{l}\stackrel{0}{0} \\
\text { o }\end{array}$ & - & - & - & $\Xi$ & \pm & 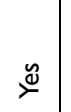 & $\begin{array}{l}0 \\
\stackrel{0}{0} \\
z\end{array}$ & & 2 & น゚ & $\stackrel{N}{N}$ & $\overline{0}$ & $\stackrel{\circ}{m}$ & 旁 & $\S$ & 요 & $\stackrel{\circ}{0}$ & $\frac{0}{10}$ & $\stackrel{m}{\ddot{q}}$ \\
\hline $\begin{array}{l}0 \\
\stackrel{0}{0} \\
\text { Z }\end{array}$ & - & - & - & $\stackrel{\Delta}{\hat{O}}$ & $r$ & $\stackrel{\tilde{\nu}}{\check{\nu}}$ & $\begin{array}{l}0 \\
\stackrel{0}{0} \\
z\end{array}$ & & $\stackrel{\infty}{\sim}$ & กิ & $\pi$ & ชี & $\stackrel{\stackrel{\sim}{m}}{\underline{m}}$ & $\frac{\stackrel{\infty}{\delta}}{\frac{\delta}{\infty}}$ & 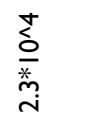 & $\underline{\underline{n}}$ & $\underline{\underline{n}}$ & $\begin{array}{c}m \\
\substack{q \\
\sigma}\end{array}$ & $\begin{array}{l}\infty \\
\dot{q} \\
\dot{q}\end{array}$ \\
\hline 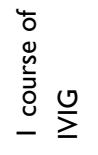 & $\stackrel{+}{+}$ & ஓ्ల & - & ב & 0 & $\stackrel{\tilde{\nu}}{\check{\nu}}$ & $\begin{array}{l}0 \\
\text { ¿े } \\
z\end{array}$ & & ホ & ț & ๓̊ & $\bar{\circ}$ & $\stackrel{\infty}{\infty}$ & 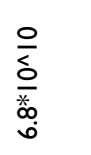 & 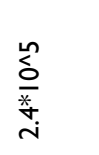 & ๕ & $\stackrel{\infty}{\stackrel{\infty}{m}}$ & $\stackrel{+}{\overleftarrow{\sigma}}$ & $g$ \\
\hline 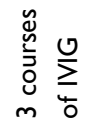 & $\overline{\mathrm{I}}$ & 이 & - & $\stackrel{\substack{0 \\
O}}{\circ}$ & n & $\stackrel{y}{\check{\nu}}$ & $\begin{array}{l}\stackrel{0}{0} \\
\stackrel{0}{z}\end{array}$ & & o & ช్ & t & $\overline{0}$ & $\stackrel{⿱ 亠 乂}{r}$ & $\frac{\frac{0}{\delta}}{\frac{o}{*}}$ & $\frac{\hat{s}}{\stackrel{0}{*}}$ & 으 & 으 & $\hat{\sigma}$ & 足 \\
\hline 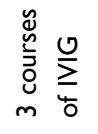 & $\stackrel{\sigma}{\infty}$ & $=$ & - & 苚 & 0 & 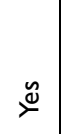 & 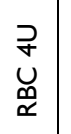 & & $\widehat{ర}$ & $q$ & n & $\overline{0}$ & $\stackrel{0}{0}$ & 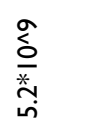 & 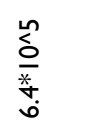 & $\underline{\underline{n}}$ & $\stackrel{\circ}{N}$ & 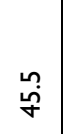 & $\stackrel{\stackrel{n}{i n}}{\stackrel{m}{n}}$ \\
\hline 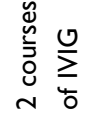 & $\stackrel{\text { นn }}{\sim}$ & $\bar{\sim}$ & - & $\stackrel{m}{o}$ & $=$ & $\stackrel{\tilde{y}}{\check{y}}$ & 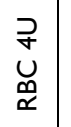 & & ஜ & น & $\widehat{\infty}$ & ชี & $\stackrel{m}{=}$ & $\S$ & $\S$ & œ & $\stackrel{2}{\wedge}$ & $\bar{\infty}$ & $\stackrel{\infty}{\circ}$ \\
\hline 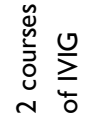 & $\stackrel{\circ}{+}$ & $\stackrel{ \pm}{\sim}$ & - & 灾 & $\simeq$ & 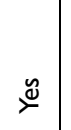 & $\begin{array}{l}\stackrel{0}{0} \\
\text { Z }\end{array}$ & & $\stackrel{n}{\wedge}$ & $\hat{o}$ & 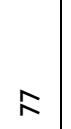 & $\overline{0}$ & ๑ீ & $\S$ & $\S$ & $\stackrel{\circ}{\circ}$ & $\overline{\underline{m}}$ & î̀ & $\stackrel{\stackrel{n}{S}}{6}$ \\
\hline 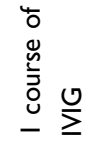 & $\stackrel{\sim}{\sim}$ & $\simeq$ & - & 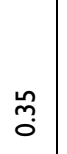 & $r$ & $\stackrel{\tilde{y}}{\check{\nu}}$ & $\begin{array}{l}0 \\
\text { ¿े }\end{array}$ & & $\tilde{3}$ & $\tilde{0}$ & $\approx$ & ธี & $\stackrel{\infty}{\infty}$ & $\S$ & $\S$ & 음 & 占 & $\stackrel{m}{n}$ & $\frac{n}{n}$ \\
\hline 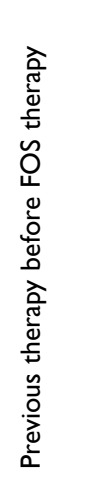 & 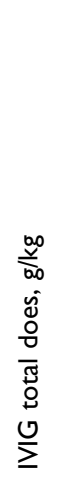 & 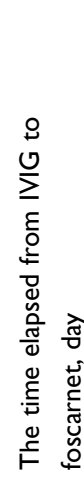 & 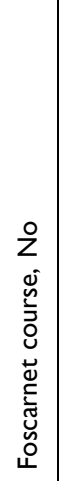 & 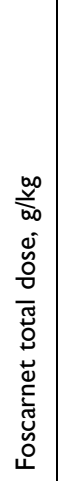 & 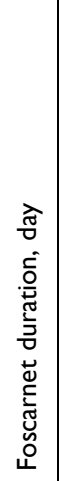 & 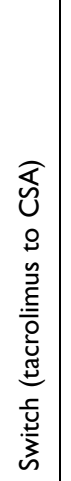 & 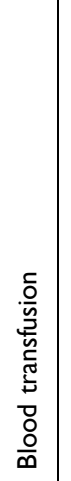 & 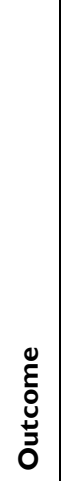 & 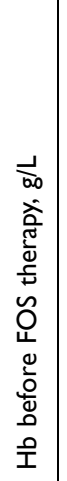 & 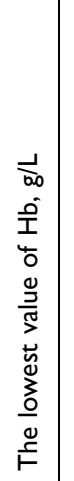 & 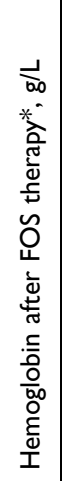 & 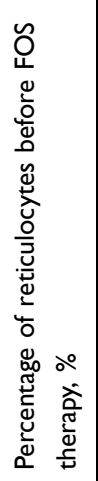 & 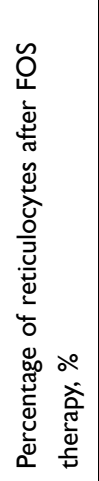 & 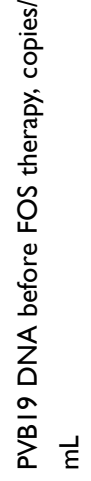 & 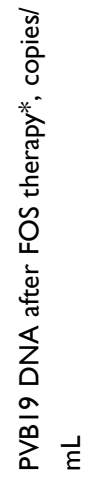 & 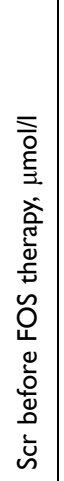 & 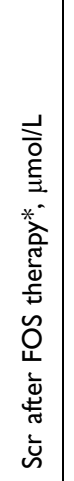 & 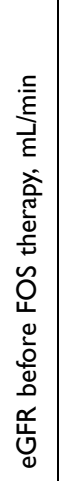 & 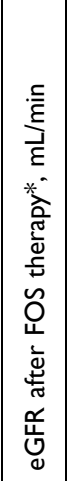 \\
\hline
\end{tabular}




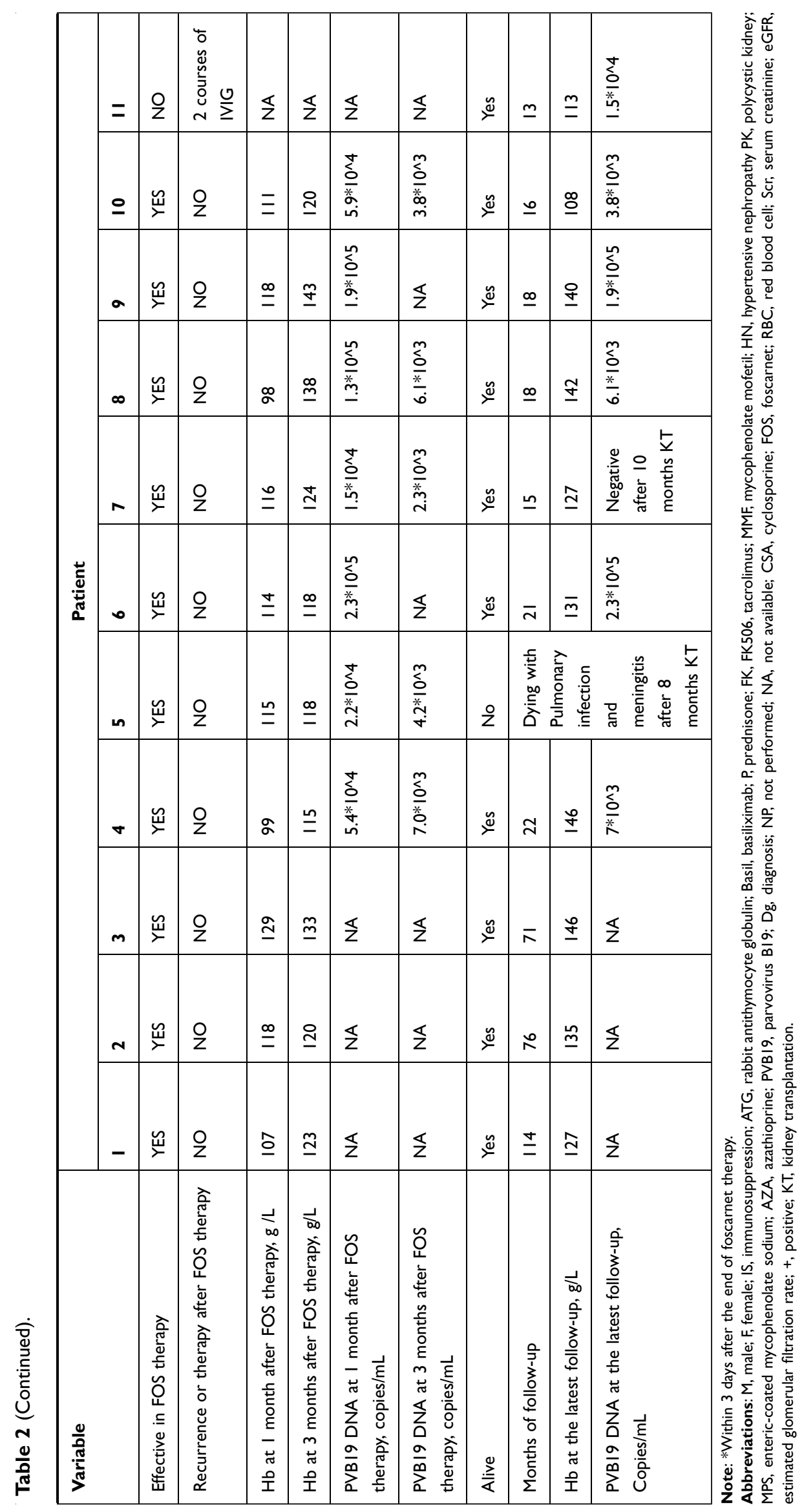




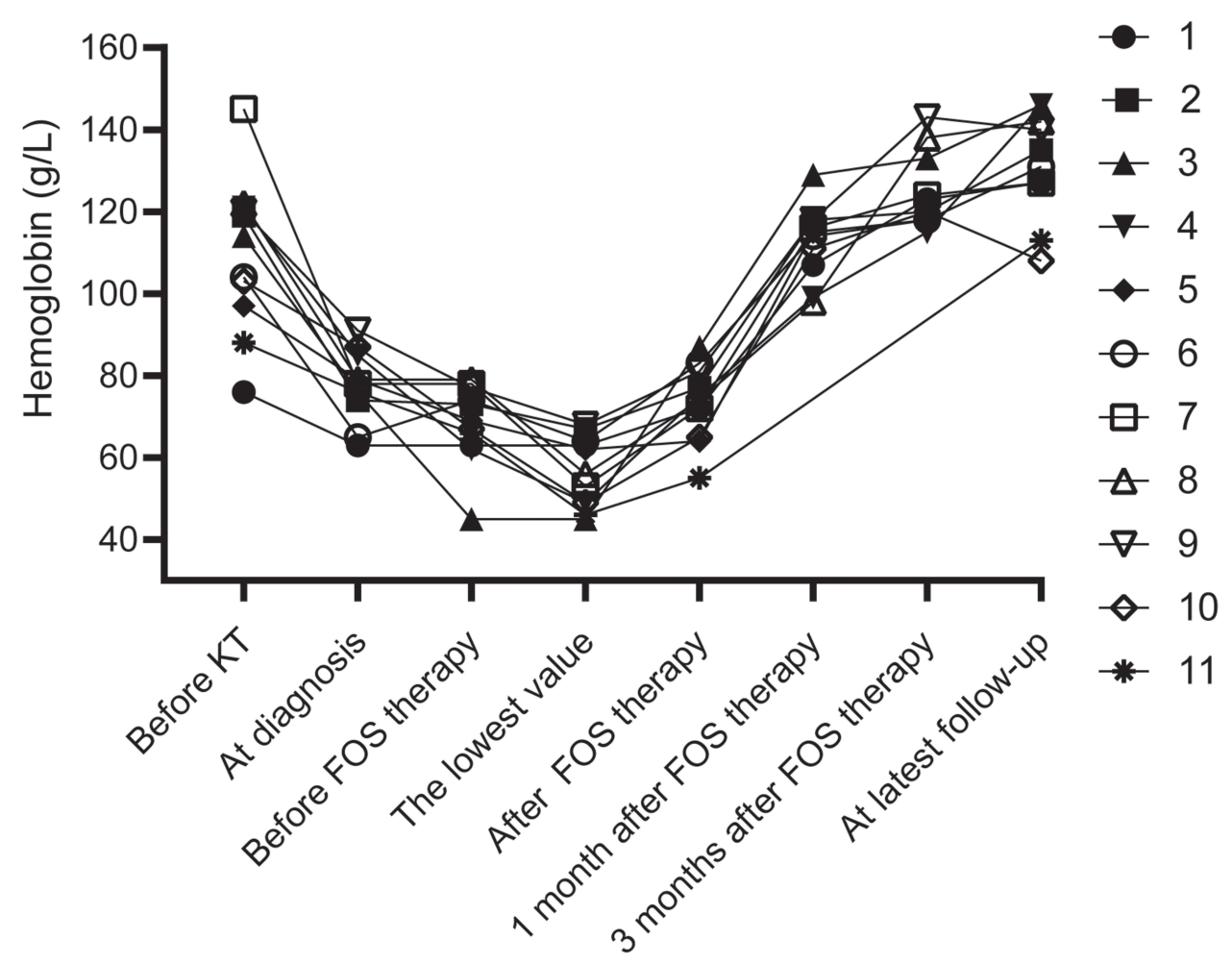

Figure 2 The change trend of hemoglobin in II patients treated with foscarnet therapy.
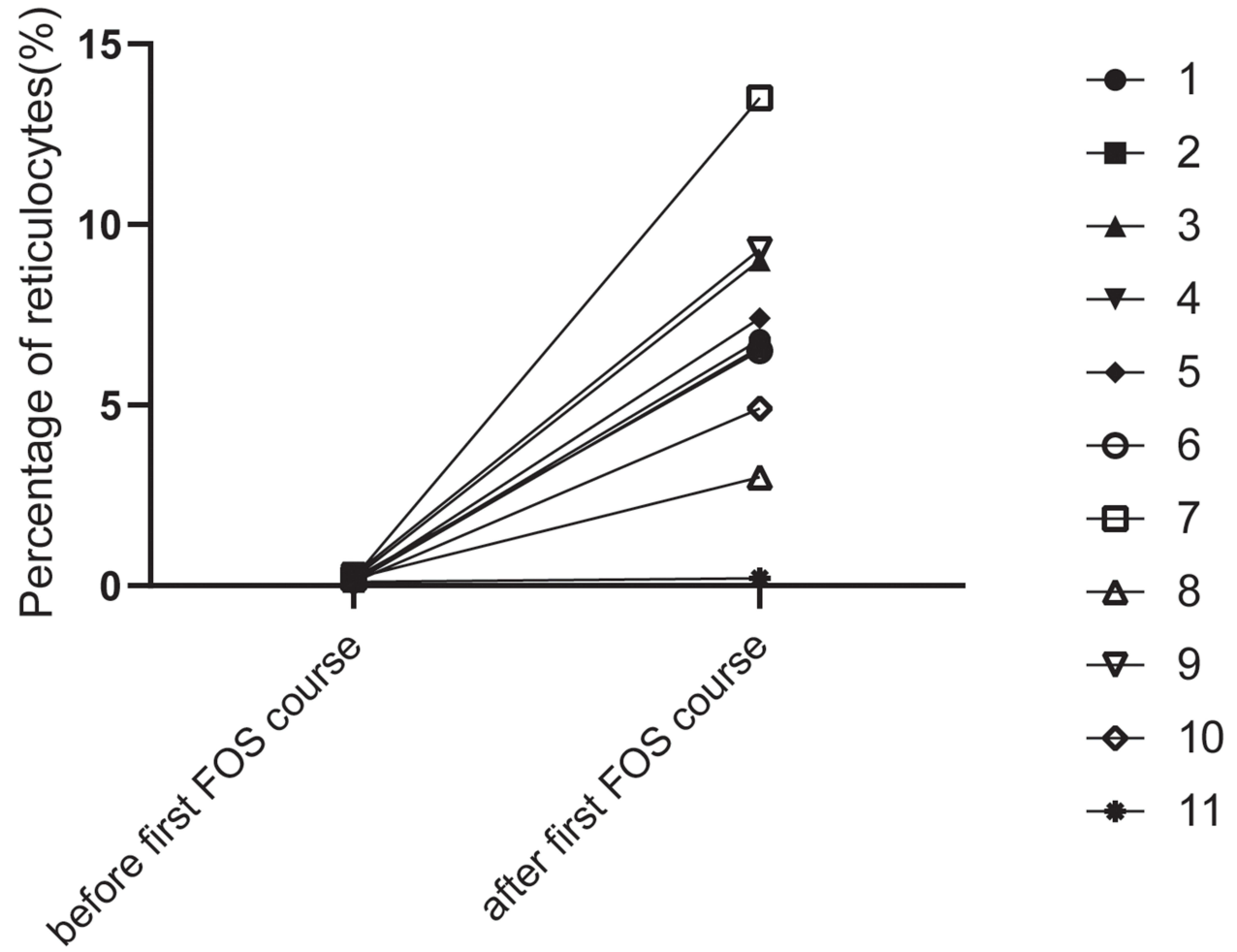

Time point

Figure 3 The change trend of percentage of reticulocytes in II patients treated with foscarnet therapy. 


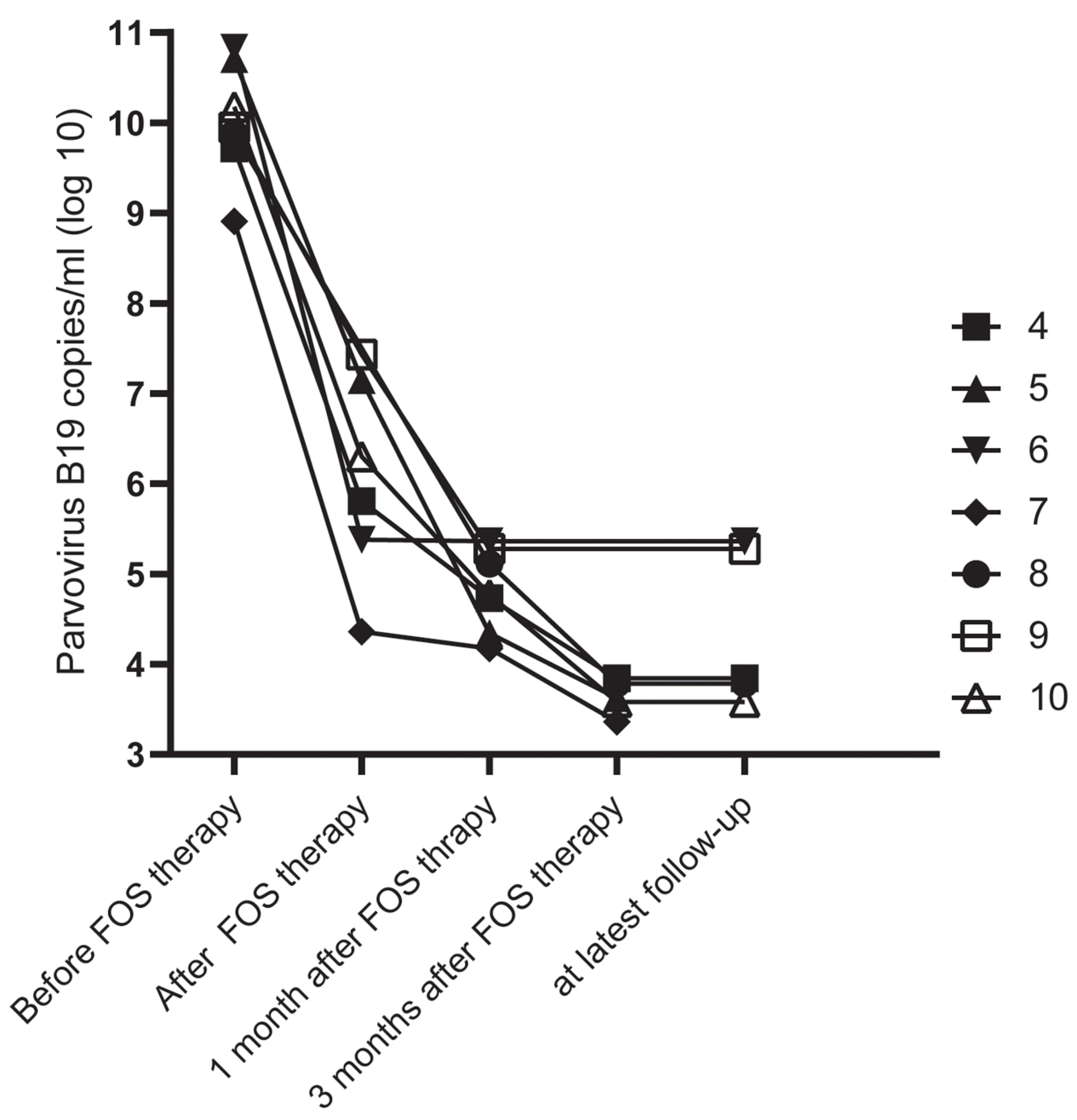

Figure 4 The change trend of serum genome copy number of parvovirus BI9 in 7 patients effectively treated with foscarnet therapy.

DNA detections were routinely carried out in KTR center was up to $2.3 \%$ (48/2113). Approximately $70 \%$ of after year of 2015, the overall incidence of PVB19- PVB19-PRCA occurred within the first three months after PRCA over 5-year period (year of 2015 to 2019) at our kidney transplantations and the median time of parvovirus

Table 3 The Clinical Characteristics of 10 Patients with Foscarnet Therapy Effectively for PVBI9-PRCA

\begin{tabular}{|c|c|c|}
\hline & Before Foscarnet Treatment & After Foscarnet Treatment \\
\hline Hemoglobin, g/L & $68.5 \pm 9.3$ & $73.2 \pm 8.8$ \\
\hline Percentage of reticulocytes, $\%$ & $0.1 \pm 0.0$ & $7.6 \pm 2.9$ \\
\hline Serum genome copy number of parvovirus B 19, copies/mL & $6.5^{*} 10^{\wedge} 9$ & $1.3^{*} 10^{\wedge} 6$ \\
\hline Scr, $\mu \mathrm{mol} / \mathrm{L}$ & $122.9 \pm 29.5$ & $133.5 \pm 35.9$ \\
\hline$P$ value & 0.61 & \\
\hline eGFR, $\mathrm{mL} / \mathrm{min}$ & $57.7 \pm 11.4$ & $56.1 \pm \mid 4.8$ \\
\hline$P$ value & 0.60 & \\
\hline $\begin{array}{l}\text { Hb at I month after foscarnet treatment, g/L } \\
\mathrm{Hb} \text { at } 3 \text { months after foscarnet treatment, g/L } \\
\mathrm{Hb} \text { at the latest follow-up, g/L }\end{array}$ & & $\begin{array}{l}112.5 \pm 8.8 \\
125.2 \pm 9.0 \\
|3| .5 \pm 12.5\end{array}$ \\
\hline
\end{tabular}


B19 infection was $1.25-2$ months after $\mathrm{KT}^{11-13}$ In our study, 46 (92\%) recipients occurred PVB19-PRCA within first three months and the median time of diagnosis was 34.5 days, both of which were in good agreement with literature reports. Infections occur throughout the year, but especially in late winter to early summer. ${ }^{14}$ Interestingly, there are a large number of cases occur from April to June in our cases, which is also in accordance with the literature.

PVB19-PRCA can be diagnosed by the direct detection with a viral DNA PCR test or bone marrow examination, especially in recipients who presented progressive anemia, reticulocytopenia, and do not respond well to erythropoietin. $^{15}$ In our study, all patients had typical clinical manifestations as well as the result of viral detection were positive. In PRCA, bone-marrow examination shows giant pronormoblasts or the absence of erythroid precursors. However, it was performed in 33 patients, only 19 cases demonstrated PRCA. One of the explanations for the low incidence of PRCA bone marrow evidence is probably the related to the operation time and quality of bone marrow materials.

From the literature reviewed, so far, the therapy options for PVB19-PRCA include any or all of the following: administration of IVIG, decreased immunosuppression regimen to improve recipient's immune system, conservative therapy, including red-cell transfusion, erythropoietin or surveillance. ${ }^{14}$ IVIG containing antiparvovirus antibodies has been widely used and appears to be beneficial in a substantial number of kidney recipients with pure red cell aplasia related to human parvovirus B19 infection. However, the optimal duration and dosing regimen of IVIG therapy for parvovirus B19 infection have yet to be established. The effective dose of IVIG for most patients with up to $2.3 \pm 1.3 \mathrm{~g} / \mathrm{kg}$ per course. Unfortunately, the recurrence rate of IVIG in a heterogeneous population is up to $33 \%{ }^{8}$ In our cases, the mean dose of IVIG was 2.8 $\pm 1.3 \mathrm{~g} / \mathrm{kg}$ in 45 patients for the first-onset of PVB19PRCA. Among them, 10 of $45(22.2 \%)$ patients had relapse with varying number of times and then were given IVIG again after recurrence, including 5 patients presented only 1 relapse and 5 patients developed 2 or more relapses. Furthermore, IVIG has potential toxicity and its cost is rather high, especially for patients with multiple relapses. The common side effects of IVIG treatment include fever, shivering, fatigue, headache, nausea, vomiting, myalgia, hypertension and renal failure. ${ }^{16,17}$ Based on this background, we attempted to practice foscarnet therapy as an exploratory treatment in 6 patients with a good allograft function (eGFR $>45 \mathrm{~mL} / \mathrm{min}$ ) but relapse after IVIG therapy. To our satisfaction, the outcomes were not bad. Therefore, the therapeutic effect and safety were observed in 5 patients treated with foscarnet for the first-onset of PVB19-PRCA. Although limited to 11 cases, to the best of our knowledge, this is the first reported series in the treatment of parvovirus B19 infection with foscarnet therapy. Nowadays, there are no specific antiviral drugs for the treatment of parvovirus B19 infection and the B19 vaccine project is not available. ${ }^{14}$

Foscarnet as a broad-spectrum and second-line antiviral drug, which is mainly used in the treatment of ganciclovir-resistant cytomegalovirus (CMV) infection in renal transplant recipient. As an analog of pyrophosphate, foscarnet can inhibit the DNA chains from extending further by reversibly and selectively blocking the binding site of the viral DNA polymerase enzyme. In our study of parvovirus as a single-stranded linear DNA virus, we make use of this feature to attempt the use of foscarnet therapy in KTR with PVB19-PRCA. The most important adverse effect of foscarnet is nephrotoxicity, but the renal function and pathological changes are reversible, as long as the fibrosis is not serious and the patient receives enough hydration. ${ }^{18}$ We selected patients with good allograft function (the eGFR $>45 \mathrm{~mL} / \mathrm{min} / 1.73 \mathrm{~m}^{2}$ ) to be treated with foscarnet therapy and given $1000 \mathrm{~mL}$ per day adequate hydration. Iwami et al reported that a renal transplant patient with ganciclovir-resistant cytomegalovirus infection was treated successfully with foscarnet. Nevertheless, after a period of time, kidney allograft biopsy revealed crystal deposition in the tubules, suggesting tubulointerstitial damage perhaps caused by foscarnet. However, allograft damage recovered spontaneously after foscarnet discontinuation. ${ }^{19}$ This illustrates that foscarnet is relatively safe in renal recipients with good allograft function, but it is necessary to closely observe the changes of renal function.

Overall, we have got satisfying result of foscarnet therapy for PVB19-PRCA in KTR. In our study, clinical observation showed that the effective rate of IVIG reached $100 \%$ but the recurrence rate was $22.2 \%(10 /$ $45)$. In foscarnet therapy, the effective rate was $90.9 \%$ $(10 / 11)$ and there was no recurrence. Although these results suggest that the foscarnet therapy had almost no relapse once it works, they remain inconclusive due to the low number of patients. It is regrettable that 1 patient had a poor response to foscarnet therapy and her percentage of 
reticulocytes was $0.2 \%$ after treatment. Except for this patient, we can observe in other 10 patients that there is a significant improvement in hemoglobin and no significant deterioration in allograft function after foscarnet therapy (Table 3), indicating that foscarnet is effective and relatively safe in these patients and can be used as an alternative therapy in addition to IVIG therapy. During follow-up, 10 patients did not show clinical or laboratory signs of PVB19 infection with a good outcome in terms of both renal function and graft survival except for 1 patient who died of pulmonary infection and meningitis. Parvovirus B19 DNA can be detected at low-grade levels in the peripheral blood of normal hosts within months or even years after primary infection and remission of symptoms. $^{20-22}$ In our cases, only 1 patient was parvovirus B19 viremia negative, and the rest had ongoing viremia, which shows that our goal is to improve reticulocytes and hematocrit rather than generate a negative result of PVB19 DNA.

Several limitations of our study are worth declaring. First, the present study was limited by its small number cases and retrospective design. Another limitation was that there was no periodic detection of PVB19 quantitative PCR during follow-up to evaluate virologic behavior and the extermination of viremia after the improvement of hemoglobin and reticulocytes. However, PVB19 DNA PCR at low level are allowed as long as there is no obvious drop in reticulocyte count and hematocrit. Lastly, some patients received blood transfusion owing to low hemoglobin levels, which can influence the assessment of efficacy of foscarnet to some extent.

In conclusion, foscarnet therapy seems to be effective and safe in KTR with PVB19-PRCA. Furthermore, foscarnet does not appear to be worse than IVIG. Therefore, we proposed that foscarnet may be an alternative therapy for PVB19-PRCA in KTR with good allograft function in addition to IVIG therapy. Broader, prospective, multicenter studies are needed to better define the optimal schedule of foscarnet treatment for kidney transplant recipients.

\section{Acknowledgments}

The authors thank technician Yin Chen for the detection of parvovirus B19.

\section{Funding}

This study was funded by the National health and Family planning Commission of the People's Republic of China
(WKJ-ZJ-1924) and National Natural Science Foundation of China (81770752, 81970651).

\section{Disclosure}

The authors report no conflicts of interest for this work.

\section{References}

1. Waldman M, Kopp JB. Parvovirus B19 and the kidney. Clin J Am Soc Nephrol. 2007;2(Suppl 1):S47-56. doi:10.2215/CJN.01060307

2. Cossart YE, Field AM, Cant B, Widdows D. Parvovirus-like particles in human sera. Lancet. 1975;1(7898):72-73. doi:10.1016/s01406736(75)91074-0

3. Servant-Delmas A, Morinet F. Update of the human parvovirus B19 biology. Transfus Clin Biol. 2016;23(1):5-12. doi:10.1016/j. tracli.2015.11.006

4. Kurtzman GJ, Cohen B, Meyers P, Amunullah A, Young NS. Persistent B19 parvovirus infection as a cause of severe chronic anaemia in children with acute lymphocytic leukaemia. Lancet. 1988;2(8621):1159-1162. doi:10.1016/s0140-6736(88)90233-4

5. Frickhofen N, Chen ZJ, Young NS, Cohen BJ, Heimpel H, Abkowitz JL. Parvovirus B19 as a cause of acquired chronic pure red cell aplasia. Br J Haematol. 1994;87(4):818-824. doi:10.1111/ j.1365-2141.1994.tb06743.x

6. Ammus SS, Yunis AA. Acquired pure red cell aplasia. Am J Hematol. 1987;24(3):311-326. doi:10.1002/ajh.2830240312

7. Alangaden GJ, Thyagarajan R, Gruber SA, et al. Infectious complications after kidney transplantation: current epidemiology and associated risk factors. Clin Transplant. 2006;20(4):401-409. doi:10.1111/j.1399-0012.2006.00519.x

8. Crabol Y, Terrier B, Rozenberg F, et al. Intravenous immunoglobulin therapy for pure red cell aplasia related to human parvovirus b19 infection: a retrospective study of 10 patients and review of the literature. Clin Infect Dis. 2013;56(7):968-977. doi:10.1093/cid/ cis 1046

9. Garikapati S, Nguyen M. Foscarnet. StatPearls; 2021.

10. Thongprayoon C, Khoury NJ, Bathini T, et al. Epidemiology of parvovirus B19 and anemia among kidney transplant recipients: a meta-analysis. Urol Ann. 2020;12(3):241-247. doi:10.4103/UA. UA_89_19

11. Eid AJ, Brown RA, Patel R, Razonable RR. Parvovirus B19 infection after transplantation: a review of 98 cases. Clin Infect Dis. 2006;43 (1):40-48. doi:10.1086/504812

12. An HPH, Diem HT, Cuong NT. Parvovirus B19-associated anemia in kidney transplant recipients: a single-center experience. Transplant Proc. 2019;51(8):2693-2696. doi:10.1016/j.transproceed.2019.03.076

13. Gallinella G, Manaresi E, Venturoli S, Grazi GL, Musiani M, Zerbini M. Occurrence and clinical role of active parvovirus B19 infection in transplant recipients. Eur J Clin Microbiol Infect Dis. 1999;18(11):811-813. doi:10.1007/s100960050406

14. Landry ML, Hayden RT, Wolk DM, Carroll KC, Tang Y-W. Parvovirus B19. Microbiol Spectr. 2016;4(3). doi:10.1128/microbiolspec.DMIH2-0008-2015

15. Eid AJ, Chen SF; AST Infectious Diseases Community of Practice. Human parvovirus B19 in solid organ transplantation. Am J Transplant. 2013;13(Suppl 4):201-205. doi:10.1111/ajt.12111

16. Plentz A, Wurdinger M, Kudlich M, Modrow S. Low-level DNAemia of parvovirus B19 (genotypes 1-3) in adult transplant recipients is not associated with anaemia. J Clin Virol. 2013;58(2):443-448. doi:10.1016/j.jcv.2013.07.007

17. Vo AA, Cam V, Toyoda M, et al. Safety and adverse events profiles of intravenous gammaglobulin products used for immunomodulation: a single-center experience. Clin J Am Soc Nephrol. 2006;1 (4):844-852. doi:10.2215/CJN.01701105 
18. Deray G, Martinez F, Katlama C, et al. Foscarnet nephrotoxicity: mechanism, incidence and prevention. Am J Nephrol. 1989;9 (4):316-321. doi:10.1159/000167987

19. Iwami D, Ogawa Y, Fujita H, et al. Successful treatment with foscarnet for ganciclovir-resistant cytomegalovirus infection in a kidney transplant recipient: a case report. Nephrology (Carlton). 2016;21 (Suppl 1):63-66. doi:10.1111/nep.12767

20. Kerr JR, Curran MD, Moore JE, Murphy PG. Parvovirus B19 infection-persistence and genetic variation. Scand J Infect Dis. 1995;27 (6):551-557. doi:10.3109/00365549509047066
21. Cassinotti P, Schultze D, Schlageter P, Chevili S, Siegl G. Persistent human parvovirus B19 infection following an acute infection with meningitis in an immunocompetent patient. Eur J Clin Microbiol Infect Dis. 1993;12(9):701-704. doi:10.1007/BF02009384

22. Cassinotti P, Siegl G. Quantitative evidence for persistence of human parvovirus B19 DNA in an immunocompetent individual. Eur J Clin Microbiol Infect Dis. 2000;19(11):886-887. doi:10.1007/s10096 0000384

\section{Publish your work in this journal}

Infection and Drug Resistance is an international, peer-reviewed openaccess journal that focuses on the optimal treatment of infection (bacterial, fungal and viral) and the development and institution of preventive strategies to minimize the development and spread of resistance. The journal is specifically concerned with the epidemiology of antibiotic resistance and the mechanisms of resistance development and diffusion in both hospitals and the community. The manuscript management system is completely online and includes a very quick and fair peerreview system, which is all easy to use. Visit http://www.dovepress.com/ testimonials.php to read real quotes from published authors. 